\title{
Nghề, nghiệp và tần suất viết
}

\section{Phạm Hiệp}

Điều đầu tiên tôi muốn bàn ở đây là từ khóa "người viết". Về mặt truyền thống, khi nói đến người làm nghề/nghiệp viết, ta thường nghĩ ngay đến nhà báo, nhà văn (theo nghĩa rộng tức là bao gồm cả người viết văn và viết thơ).

Trong bài này, tôi muốn mở rộng thêm một đối tượng, đó là nhà khoa học, những người mà sản phẩm chính của họ cũng được thể hiện qua việc viết bài báo khoa học/sách chuyên khảo, tham khảo.

Hai từ khóa tiếp theo là "nghề" và "nghiệp". Theo cách hiểu thông thường, khi ta nói làm nghề, nghĩa là nghề đó tạo ra thu nhập thường xuyên cho người lao động (trong khuôn khổ bài này thì là người viết), giúp họ đủ nuôi sống bản thân và gia đình, hoặc hơn nữa là có cuộc sống sung túc, giàu có.

Ngược lại, nghiệp thì chưa chắc đã đem lại thu nhập ổn định cho người viết nhưng như một nhà văn đã từng nói "cái nghiệp viết đâu phải nói bỏ là bỏ được", người viết nhiều khi không kiếm đủ tiền để sinh sống bằng hoạt động viết nhưng họ vẫn viết vì viết là "nghiệp". Cái "nghiệp" đó sẽ giúp họ có được các tác phẩm đỉnh cao.

Từ khóa cuối cùng là "tần suất" viết, đúng hơn là tần suất công bố tác phẩm. Nó xoay quanh một loạt câu hỏi kinh điển của người viết từ xưa đến 
nay: viết bao nhiêu cho đủ? Nên viết nhiều hay viết it? Viết nhanh hay viết thura?

Câu trả lời cho các câu hỏi liên quan đến vấn đề "tần suất" viết khá rõ đối với người viết văn và viết báo:

- Viết báo rõ ràng là một nghề phổ biến. Và đã là nhà báo thì phải viết đều, viết nhiều, tức là với "tần suất" cao. Báo (giấy) ngày trước hay báo mạng hiện nay yêu cầu nhà báo phải viết với tần suất cao nhất: hằng ngày. Người làm báo chuyên đề hay tạp chí thì dễ thở hơn một chút nhưng chắc cũng hiếm có nhà báo không có tuần nào không viết gì cả.

Cũng có thể có người làm báo kiếm tiền từ viết báo không đủ, ví dụ như những người làm báo tay ngang (một công chức về hưu hay một chuyên gia trong lĩnh vực nào đó), nhưng thường thì họ sẽ nói "viết báo cho vui", hiếm ai đó trong số này nói "viết báo vì đó là cái nghiệp".

- Với viết văn, mặc dù trong xã hội của chúng ta có rất nhiều người có danh xưng nhà văn nhưng rất ít người có thể sống được bằng nghề do đặc thù của văn chương là khó viết và công bố tác phẩm thường xuyên.

Ở Việt Nam, Nguyễn Nhật Ánh là một trường hợp ngoại lệ hiếm hoi sống được bằng các tác phẩm văn học của mình. Hẳn nhiên, Nguyễn Nhật Ánh cũng viết rất "đều tay" và công bố thường xuyên.

Ở bình diện quốc tế, một nhà văn khác cũng sống, thậm chí trở thành triệu phú dollar, hoàn toàn bằng tác phẩm là nữ văn sĩ Joanne Rowling, tác giả của tập truyện viễn tưởng Harry Potter.

Nói về việc này, một nhà văn trẻ (xin được giấu tên) có nhận xét, đặc điểm chung của các nhà văn sống được bằng nghề và tần suất viết thường 
xuyên là thường viết về chủ đề thiếu nhi, ngôn tình, tức là có yếu tố thị trường, giá trị thương mại có thể cao nhưng giá trị văn chương thì không chắc.

Như vậy, thực tế là phần lớn các nhà văn trong thực tế chỉ coi văn chương là nghiệp, còn sống thì phải dựa vào nghề khác. Và nghề khác, rất hay lại thường là nghề báo. Kim Dung - tác giả truyện kiếm hiệp nổi tiếng của Trung Quốc - mặc dù kiếm được rất nhiều tiền nhờ truyện chưởng, nhưng thực tế vẫn sống bằng nghề báo. Một số khác, ít hơn có hẳn một nghề nghiệp riêng.

Ví dụ, nhà văn Hồ Anh Thái còn là một nhà ngoại giao, một công chức nhà nước; nhà văn người Mỹ gốc Việt Thanh Việt còn là một giáo sư đại học; nhà văn Dương Hướng, tác giả của tiểu thuyết Bến không chồng thậm chí còn sống bằng nghề nghe có vẻ rất ít văn chương... cán bộ hải quan.

\section{Tài liệu tham khảo:}

[1] Phạm Minh Chính \& Vương Quân Hoàng. (2009). Kinh tế Việt Nam: Thăng trầm và đột phá. Nxb Chính trị Quốc gia, Hà Nội.

[2] Phạm Minh Chính \& Vương Quân Hoàng. (2008). Bối cảnh tài chính Việt Nam 1997-1998 và 2007-2008: Khoảng cách và biến đối. Nghiên cứu Kinh tế, 48(7), 3-24.

[3] Vuong, Q. H. (2018). The (ir) rational consideration of the cost of science in transition economies. Nature Human Behaviour 2 (1), 5, doi: 10.1038/s41562-017-0281-4.

[4] Vuong, Q. H., Bui, A. T., La, V. P., Nguyen, M. H., Pham, H. H., Pham, T. H., ... \& Ho, M. T. (2021). Mirror, mirror on the wall: Is economics the fairest of them all? An investigation into the social sciences and humanities in Vietnam. Research Evaluation. 
Nghiên cứu thì chắc chắn là một nghề nhưng tần suất viết của nhà nghiên cứu rõ ràng là một chủ đề ít được chú ý ở Việt Nam:

- Ở Việt Nam, việc một nhà nghiên cứu (giảng viên/nghiên cứu viên) vì tần suất công bố không đủ mà mất việc có lẽ vẫn là chuyện lạ. Nhưng với thế giới phương Tây, đó là chuyện bình thường. Tần suất công bố công trình khoa học là một trong những thước đo để đánh giá kết quả làm việc của nhà nghiên cứu. 
Trong giới khoa học có câu cửa miệng "xuất bản hay lụi tàn" (publish or perish) hàm ý nếu nhà nghiên cứu không xuất bản các công trình khoa học của mình, họ sẽ bị thải loại khỏi nghề (lụi tàn). Xu hướng này bắt đầu xuất hiện từ những năm 1960 và ngày càng mạnh mẽ hơn cho đến tận ngày nay.

Điều này nghĩa là, nhà nghiên cứu ngày nay khó còn có thể ung dung ngồi trong "tháp ngà" suy tưởng về những điều chỉ mình quan tâm và thích bao giờ viết thì viết.

Năm 2013, khi trả lời báo Guardian, GS Higgs, người từng đạt giải Nobel cùng năm đã có một chia sẻ khá thú vị: khoảng những năm 1960, khi đó ông còn là một nghiên cứu viên trẻ tuổi, đã suýt bị mất việc vì viết (công bố) ít quá.

Sự kiện bước ngoặt giúp ông giữ được hợp đồng là vì năm đó ông lọt vào danh sách rút gọn ứng viên giải Nobel (sau đó thì trượt giải) khiến cho ban chủ nhiệm khoa rút lại ý định sa thải.

- Mặc dù xu hướng chung với nhà nghiên cứu là tần suất viết phải đều. Nhưng bao nhiêu là "đều" vẫn là một câu hỏi gây tranh cãi chính bản thân trong giới này.

Rộng hơn, có 2 quan điểm về làm nghề trong giới nghiên cứu: một là, nghĩ cho đủ, làm thực nghiệm cho kỹ rồi hãy công bố, như vậy thì sẽ có các công trình kết quả tốt; hai là, cứ làm vừa phải, có kết quả thì công bố ngay, nghiên cứu tiếp theo lại dựa trên công bố trước đó phát triển tiếp, làm tốt hơn từng chút một.

Vấn đề này hấp dẫn đến mức, một nhóm nghiên cứu, bao gồm TS Lariviere (đến từ Canada), và TS Costas (đến từ Hà Lan) đã dành thời 
gian thu thập thông tin từ hơn 28 triệu nhà khoa học có công trình công bố trong giai đoạn 34 năm từ 1980-2013 để phân tích.

Kết quả nghiên cứu của nhóm sau đó được đăng trên Tạp chí PLOS One vào tháng 9-2016 với tiêu đề How Many Is Too Many? On the Relationship between Research Productivity and Impact (Bao nhiêu là quá nhiều? Về mối quan hệ giữa năng suất nghiên cứu và tác động của nó).

Kết quả đối với nhóm tác giả có công trình nghiên cứu đầu tiên trong giai đoạn 1981-1985 cho thấy: nếu nhà khoa học càng công bố nhiều công trình thì xác suất để người đó có nhiều bài trong top $1 \%$ được trích dẫn nhiều càng cao (chất lượng nghiên cứu trong khoa học được phản ánh qua số lần trích dẫn).

Quy luật này đúng cho cả 4 phân ngành lớn là: khoa học tự nhiên; khoa học xã hội và hành vi; luật, nhân văn và nghệ thuật; y dược và khoa học sức khỏe.

Mặc dù quy luật kể trên không hoàn toàn đúng với nhóm các nhà khoa học trẻ (có công trình công bố lần đầu trong giai đoạn 2009-2013), kết quả nghiên cứu của nhóm Lariviere và Costas cho thấy trong khoa học, việc cần cù và không ngừng làm việc, đóng gói sản phẩm và viết các công bố sẽ giúp nhà khoa học lên đến đỉnh cao của cả nghề và nghiệp.

Nói cách khác, công bố càng nhiều càng tốt là một công thức đảm bảo thành công đối với nhà khoa học trong sự nghiệp. Mặc dù vậy, nghiên cứu này lại không chỉ ra được liệu có một ngưỡng nào đó, mà nếu vượt qua, nhà khoa học sẽ có nhiều cơ hội hơn trong việc có nhiều bài báo lọt top được trích dẫn nhiều. 
Điều này hàm ý cho thấy, một khi đã dấn thân vào nghề nghiên cứu, muốn thành công, không còn cách nào khác, nhà khoa học sẽ phải lao động không ngừng nghỉ và phá vỡ giới hạn tri thức của mình thông qua từng công bố khoa học.

Tác giả gửi lời cảm ơn tới tiến sĩ Vương Quân Hoàng đã trao đổi, bàn bạc trong quá trình thực hiện bài viết này. 